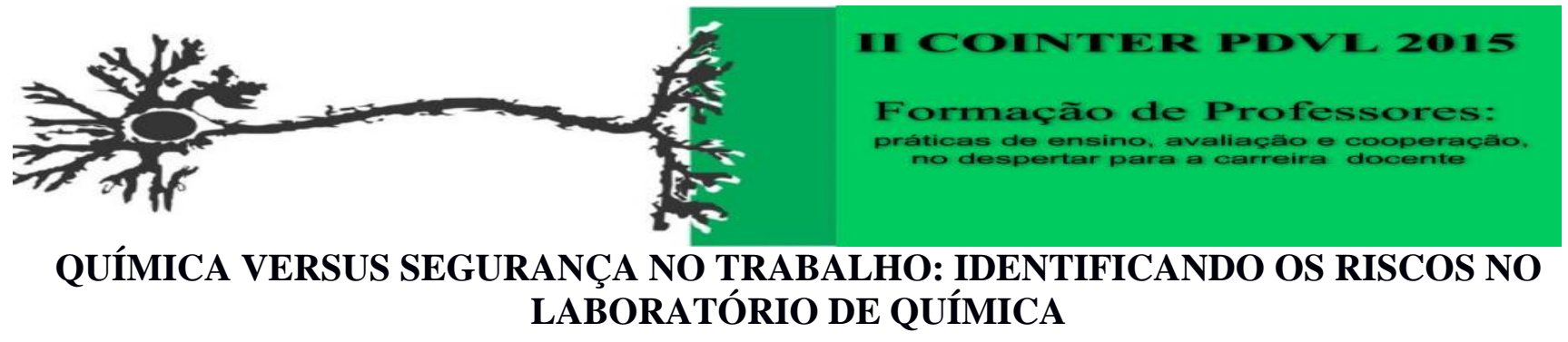

Apresentação: Comunicação Oral

Ayrton Matheus da Silva Nascimento ${ }^{1}$; Adrielly Katharine Barbosa Ferreira ${ }^{2}$; Cíntia de Abreu Arruda $^{3}$; Wlisses Guimarães Sousa ${ }^{4}$; Kilma da Silva Lima Viana ${ }^{5}$

\begin{abstract}
Resumo
O presente trabalho apresenta os resultados de uma pesquisa desenvolvida no laboratório de Química de uma escola de rede pública no município de Vitória de Santo Antão, Pernambuco. Que apresenta o objetivo principal executar o mapeamento de risco do laboratório de química. Este estudo tende apontar os riscos químicos, físicos, biológicos, ergonômicos e mecânicos ou acidentes no laboratório, onde desenvolvem atividades experimentais de química. Para isso foram desenvolvidas as seguintes etapas: (1) Conhecer o Laboratório de Química; (2) Identificar os agentes de riscos; (3) Discernir os níveis de intensidade; (4) Identificar as medidas preventivas existentes; (5) Elaborar o mapa de riscos sobre a planta do Laboratório de Química. Após as etapas, foram elencados os riscos ambientais, intensidade e tamanho baseado a NR 05. De acordo com o mapa de riscos, foram identificados todos os tipos de riscos ambientais, apresentando com a maior intensidade o risco químico no processo de prática de ensino.
\end{abstract}

Palavras-chave: laboratório de química, mapa de risco, riscos ambientais; segurança no trabalho

\title{
INTRODUÇÃO
}

Este trabalho parte da iniciativa de desenvolver e executar o mapeamento de riscos no Laboratório de Química de uma escola do Ensino Médio, com o intuito de identificar os riscos presentes neste ambiente de Ensino e pesquisa.

Atualmente, são várias discussões presentes no âmbito da Química e da Segurança do trabalho no sentido de desenvolver estratégicas que visem despertar nos demais atores sociais presentes no ambiente escolar a formação de cultura de proteção. Tratar a proteção pedagogicamente, bem como possibilitar vivências interdisciplinares é sempre um grande desafio. Assim, objetiva-se desenvolver experiência interdisciplinares a partir da interligação das áreas de química e segurança do trabalho a partir da temática de "Mapa de Riscos".

Inicialmente, cumpre conceituar Biossegurança, que é o conjunto de ações voltadas para a prevenção, e proteção do trabalhador, minimização de riscos inerentes às atividades de pesquisa, produção, ensino, desenvolvimento tecnológico e prestação de serviços, visando à saúde do homem, dos animais, a preservação do meio ambiente e a qualidade dos resultados (TEIXEIRA, VALLE, 1996).

\footnotetext{
${ }^{1}$ Licenciatura em Química, Instituto Federal de Pernambuco (IFPE - CVSA), E-mail: ayrthon.matheus@gmail.com

${ }^{2}$ Gestão em Segurança do Trabalho, Faculdade Osman Lins (FACOL), E-mail: adrielly.katharine@gmail.com

${ }^{3}$ Licenciatura em Química, Instituto Federal de Pernambuco (IFPE - CVSA), cintiaarruda@outlook.com Graduada em

${ }^{4}$ Docente do Instituto Federal de Pernambuco (IFPE - CVSA), E-mail: wlisses.guimaraes@vitoria.ifpe.edu.br

${ }^{5}$ Docente do Instituto Federal de Pernambuco (IFPE - CVSA), E-mail: kilma.viana@vitoria.ifpe.edu.br
} 
As práticas experimentais e aulas contextualizadas dão uma dinamicidade ao processo de ensino e aprendizagem, tornando-o mais significativo. A escolha da temática "Mapa de Risco" será tratada a partir de um duplo olhar: da química e da Segurança do Trabalho, analisando o Laboratório de Química de uma escola de ensino médio para que os discentes e os docentes possuam um ambiente escolar protegido.

De acordo com a Norma Regulamentadora - NR4 (SESMT - Serviço Especializado em Engenharia de Segurança e em Medicina do Trabalho), laboratórios de química se encaixam no perfil do disposto, pois são ambientes considerados insalubres e periculosos, nos quais os profissionais estão em contato direto com reagentes químicos e equipamentos (fontes de calor e eletricidade), que podem representar riscos à saúde do mesmo.

Deste modo, este trabalho descreve o procedimento para elaboração de um mapa de risco de um Laboratório de Experimentação em Química, detectando os riscos existentes bem como suas intensidades, a sistemática adequada exigida pela CIPA (Comissão Interna de Prevenção de Acidentes), sancionada através da Norma Regulamentadora - NR5.

\section{FUNDAMENTAÇÃO TEÓRICA}

Segundo Sivieri (1999), o mapa de riscos é uma representação gráfica com diversas nomenclaturas como: esboço, croqui e layout, de uma das partes ou de todo o processo produtivo da empresa, onde se registram os riscos e fatores de risco a que os trabalhadores estão expostos, direta ou indiretamente, ao processo e organização do trabalho e às condições de trabalho. É elaborado pelos cipeiros e demais trabalhadores tendo como principais recursos suas percepções e opiniões nas avaliações dos postos de trabalho.

Segundo Toledo apud Luciano (2000) para iniciar o desenvolvimento do mapa de riscos é necessário analisar os seguintes agentes:

- Físicos: são formas de energia que estão expostas aos trabalhadores, como: ruídos, vibrações, pressões anormais, temperaturas extremas, radiações ionizantes, bem como o infrassom e o ultrassom.

- Químicos: são substâncias, compostos ou produtos com capacidade de penetrar no organismo humano por meio das vias respiratórias na forma de: poeiras, fumos, névoas, neblinas, gases e vapores, ou de acordo com a atividade realizada a exposição aos agentes químicos pode ser por contato ou absorção através da pele ou ingestão.

Já segundo Drummond (1994) os agentes Físicos são através do contato com certos micróbios e animais no ambiente de trabalho surge os chamados riscos biológicos, que podem penetrar no 
corpo do trabalhador por ingestão, pela respiração ou pela pele. O mesmo destaca que os Agentes Ergonômicos estão relacionados com a organização e a execução das tarefas. Estes riscos provocam nos trabalhadores distúrbios fisiológicos e psicológicos provocando sérios danos a sua saúde, por ocasionarem alterações no estado emocional e no organismo, comprometendo desta forma a segurança, saúde e a sua produtividade. Já o Agentes Mecânicos existe uma diversificação a este tipo de risco, podendo estar envolvidos em máquinas e equipamentos e ferramentas defeituosas, inadequadas ou inexistentes, máquinas e equipamentos, edificações, eletricidade, sinalização, transporte de material, etc.

As atividades nos laboratórios de ensino médio são elementos importantes no fazer, ou seja, aplicar em prática o que se assimila na teoria. Esta pesquisa tem por objetivo identificar e analisar os riscos existentes no Laboratório de Química e com base nestas análises construir o mapa de risco deste setor.

\section{MATERIAL E MÉTODOS}

\section{- Campo e Sujeito}

Trata-se de uma pesquisa de abordagem qualitativa, de campo do tipo descritiva.

\section{- Instrumentos de Pesquisa}

Os dados foram coletados por meio de observações sistemáticas do Laboratório de Química de uma escola estadual, análise documental, objetivando identificar os riscos ambientais e as intensidades existentes no laboratório até a elaboração do mapa de riscos. Para a realização do presente trabalho no que diz respeito a execução do mapeamento de riscos no Laboratório de Química do Ensino Médio em uma escola pública, foram desenvolvidas as seguintes etapas: (1) Conhecer o Laboratório de Química; (2) Identificar os agentes de riscos; (3) Discernir os níveis de intensidade; (4) Identificar as medidas preventivas existentes; (5) Elaborar o mapa de riscos sobre a planta do Laboratório de Química.

\section{RESULTADOS E DISCUSSÃO}

\section{Classificações dos Riscos Ambientais}

Neto (2010) aponta serão representados por círculos de tamanhos, cores diferentes, e a intensidade de riscos, e Siveri (1996) destaca a informação da tabela por caracterização dos agentes. O tamanho do círculo indicará se o risco é grande, médio ou pequeno (quanto maior for o círculo, maior o risco) observar a figura 01 . 


\begin{tabular}{|c|c|c|}
\hline \multirow{3}{*}{$\begin{array}{l}\text { Simbologia das Cores } \\
\text { No mapa de risco, os riscos sẫo } \\
\text { representadoes e indicados por } \\
\text { circulos coloridos de três tamanhos } \\
\text { diferentes, a saber: }\end{array}$} & Risco Químico Leve & Risco Mecânico Leve \\
\hline & Risco Químico Médio & $\begin{array}{l}\text { Risco Mecânico } \\
\text { Médio }\end{array}$ \\
\hline & & Risco Mecânico \\
\hline Risco Biológico Leve & Risco Ergonômico Leve & Risco Físico Leve \\
\hline Risco Biológico Médio & $\begin{array}{l}\text { Risco Ergonômico } \\
\text { Médio }\end{array}$ & Risco Físico Médio \\
\hline Risco Biológico Elevado & $\begin{array}{l}\text { Risco Ergonômico } \\
\text { Elevado }\end{array}$ & Risco Físico Elevado \\
\hline
\end{tabular}

Fonte: Neto, 2010

\begin{tabular}{|c|c|c|}
\hline Símbolo & Proporção & Tipo de riscos \\
\hline 0 & 1 & $\begin{array}{c}\text { risco pequeno ou } \\
\text { risco médio já } \\
\text { protegido }\end{array}$ \\
\hline & 2 & $\begin{array}{c}\text { risco que gera } \\
\text { incômodo, mas } \\
\text { pode ser controlado }\end{array}$ \\
\hline & $\begin{array}{c}\text { risco que pode } \\
\text { gerar doenças, } \\
\text { mutilar e matar, não } \\
\text { apresentando } \\
\text { mecanismo para } \\
\text { redução, } \\
\text { neutralização ou } \\
\text { controle }\end{array}$ \\
\hline
\end{tabular}

Fonte: Neto, 2010

\begin{tabular}{|c|c|c|c|c|}
\hline $\begin{array}{l}\text { GRUPO I: } \\
\text { VERDE }\end{array}$ & $\begin{array}{l}\text { GRUPO II: } \\
\text { VERMELHO }\end{array}$ & $\begin{array}{l}\text { GRUPO III: } \\
\text { MARROMI }\end{array}$ & $\begin{array}{l}\text { GRUPO IV: } \\
\text { AMARELO }\end{array}$ & $\begin{array}{l}\text { GRUPO } \\
\text { AZUL }\end{array}$ \\
\hline Riscos Físicos & Riscos Quimicos & Riscos Biológicos & Riscos Ergonômicos & Riscos de Acidentes \\
\hline Ruído & Poeiras & Virus & $\begin{array}{c}\text { Esforço Físico } \\
\text { Intenso }\end{array}$ & $\begin{array}{l}\text { Arranjo físico } \\
\text { inadequado }\end{array}$ \\
\hline Vibrações & Fumos & Bactérias & $\begin{array}{c}\text { Levantamento e } \\
\text { transporte manual } \\
\text { de peso }\end{array}$ & $\begin{array}{l}\text { Máquinas e } \\
\text { equipamentos } \\
\text { sem proteção }\end{array}$ \\
\hline $\begin{array}{l}\text { Radiações } \\
\text { ionizantes }\end{array}$ & Névoas & Protozoários & $\begin{array}{l}\text { Exigência de } \\
\text { postura } \\
\text { inadequada }\end{array}$ & $\begin{array}{c}\text { Ferramentas } \\
\text { inadequadas ou } \\
\text { defeituosas }\end{array}$ \\
\hline $\begin{array}{l}\text { Radiações não } \\
\text { ionizantes }\end{array}$ & Neblinas & Fungos & $\begin{array}{c}\text { Controle rígido de } \\
\text { produtividade }\end{array}$ & $\begin{array}{l}\text { Iluminação } \\
\text { inadequada }\end{array}$ \\
\hline Frio & Gases & Parasitas & $\begin{array}{l}\text { Imposição de } \\
\text { ritmos excessivos }\end{array}$ & Eletricidade \\
\hline Calor & Vapores & Bacilos & $\begin{array}{c}\text { Trabalho em turno } \\
\text { e noturno }\end{array}$ & $\begin{array}{l}\text { Probabilidade de } \\
\text { incêndio ou } \\
\text { explosão }\end{array}$ \\
\hline Pressões anormais & $\begin{array}{c}\text { Substâncias, } \\
\text { compostos ou } \\
\text { produtos químicos } \\
\text { em geral }\end{array}$ & & $\begin{array}{l}\text { Jornada de } \\
\text { Trabalho } \\
\text { prolongadas }\end{array}$ & $\begin{array}{c}\text { Armazenamento } \\
\text { inadequado }\end{array}$ \\
\hline Umidade & & & $\begin{array}{l}\text { Monotonia e } \\
\text { repetitividade }\end{array}$ & $\begin{array}{c}\text { Animais } \\
\text { peçonhentos }\end{array}$ \\
\hline
\end{tabular}

Fonte: Siveri, 1996

\section{ELABORAÇÃO DO MAPA DE RISCOS}




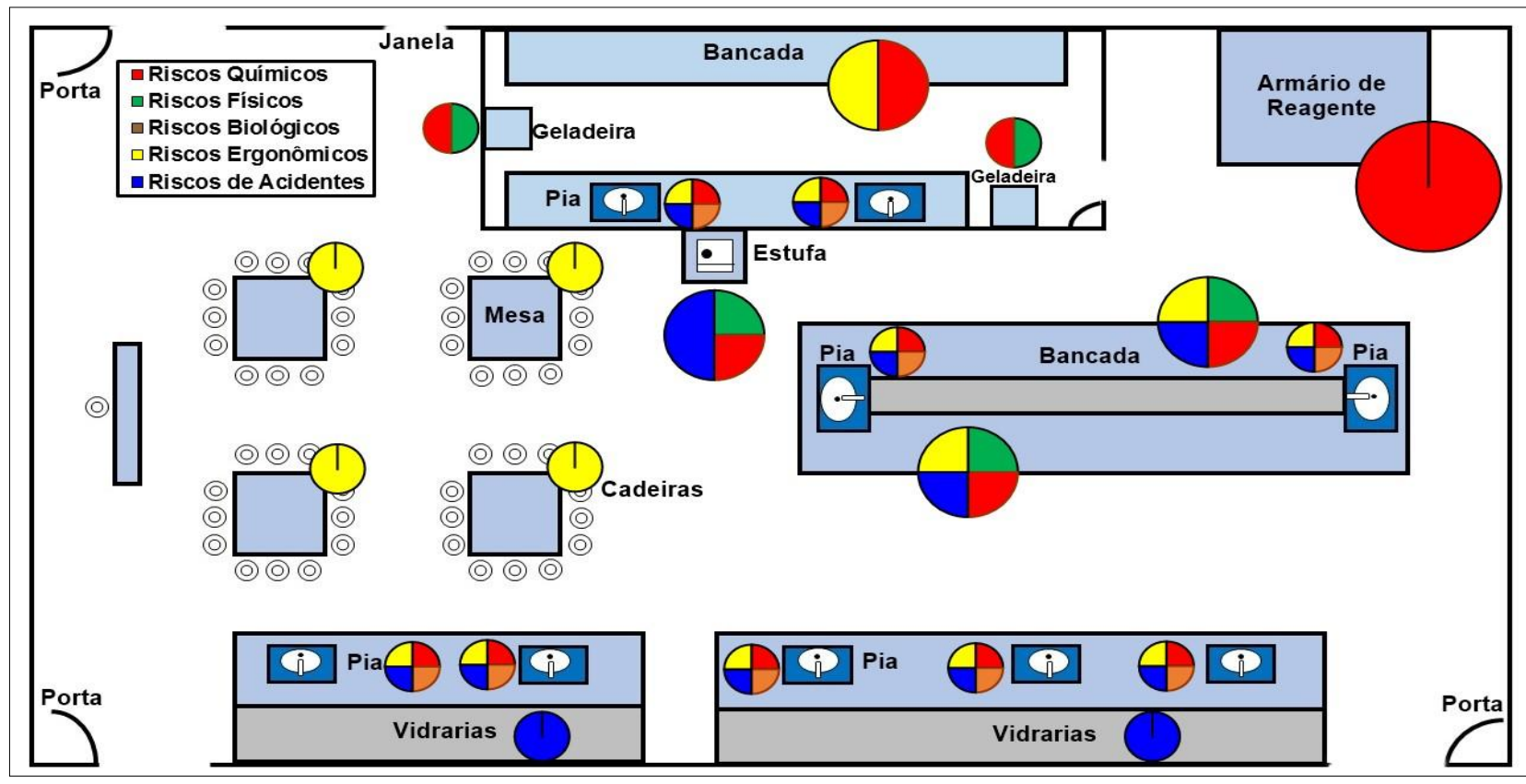

Figura 01: Mapa de Risco do Laboratório de Química

Foram analisados todos os tipos de riscos no laboratório de Química com a maior ênfase ao risco químico, que foi apontado em maior afluxo e habitualmente mais presente em quase todos a área. A ordem decrescente dos tipos de agentes analisada foi: Risco Químico > Risco Ergonômico > Risco de Acidentes > Risco Biológicos > Riscos Físico.

Foram detectados dezesseis (16) riscos ambientais sendo cinco (05) químicos, quarto (04) de acidentes, três (03) ergonômicos, três (03) físicos e um (01) biológicos, entretanto mostram diferentes intensidades no laboratório de química. Neste caso, podemos analisar esses dados por meio de estatística descritiva no gráfico 01.

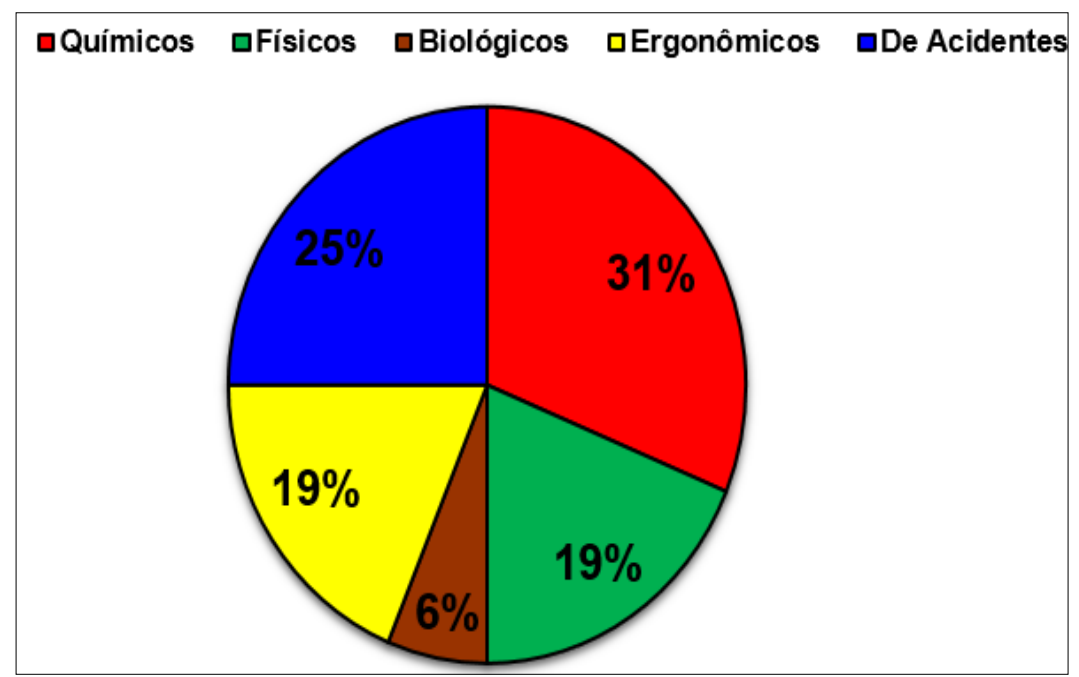

Gráfico 01: Distribuição dos 16 riscos ambientais no Laboratório de Química

\section{INTENSIDADE DO RISCOS}


A intensidade do risco foi classificada de acordo com o laboratório, as condições de aula experimental e precipuamente com os agentes identificados na área. Desta maneira a proporção das áreas está assimilado entre pequeno, médio e grande. As áreas, sala de armazenamento de reagentes, bancadas e lavatórios, apresentaram grau de intensidade do risco pequeno, médio e grande. As demais áreas exibiram grau pequeno, médio e grande. Isso justifica devido às atividades experimentais de química e os agentes encontrados em cada área.

Observa-se no gráfico 02 que no laboratório de Química a maior intensidade que os demais, foi no armário de reagente, ou seja, o local que mais apresentou intensidade de nível grande. Isso justifica devido ser o local mais crítico pela presença de reagentes químicos podendo causar vários problemas aos alunos.

A escola alerta, tanto disponibiliza aos alunos alguns equipamentos de proteção individual: luvas, óculos, máscaras, orientando aos mesmos que venham com sapato fechado, com calça, bata longa, que o ponto precípuo é a proteção contra os riscos constante.

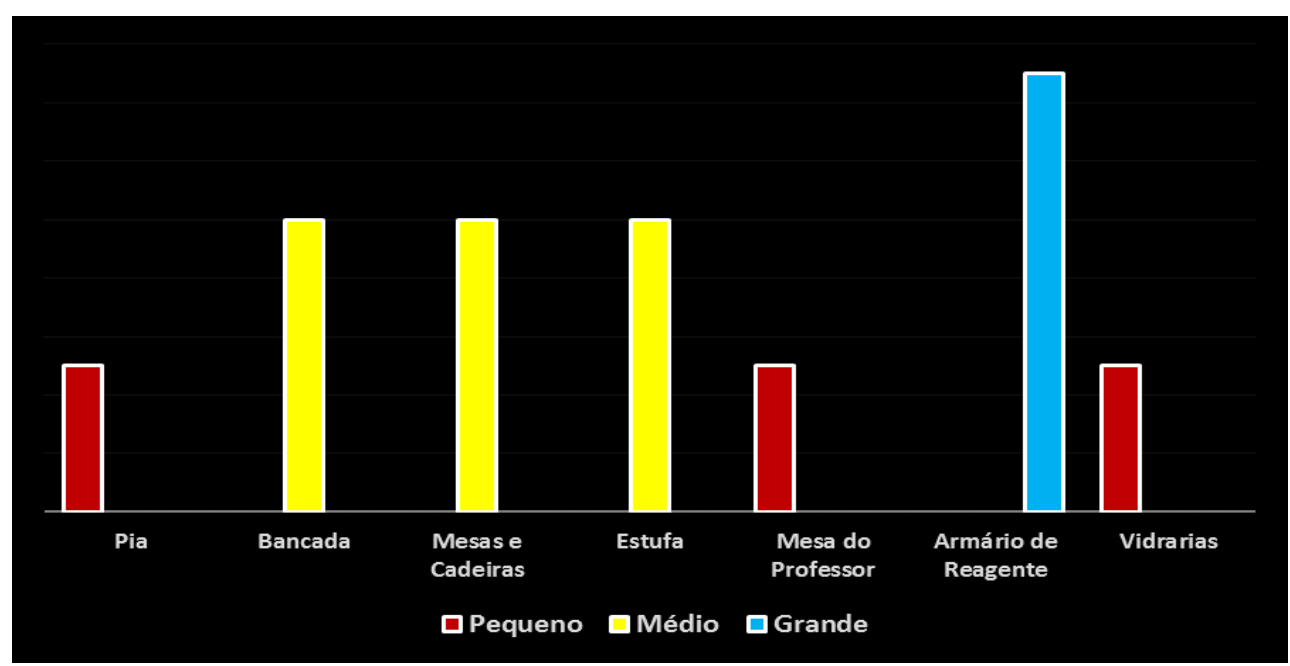

Gráfico 02: Intensidade de Riscos do Laboratório de Química

\section{Análise Local do Mapa de Risco}

De acordo com a análise do local pode-se observar máquinas, equipamentos, bancadas, armários de reagentes, geladeira e etc, em cada local foi descoberto riscos ambientais de proporções distintas, assim como mostra a tabela 01. 


\begin{tabular}{l|l}
\hline Pia & Ergonômicos, Acidentes, Biológicos, Químicos \\
\hline Bancada & Ergonômicos, Acidentes, Físicos, Químicos \\
\hline Mesas e Cadeiras & Ergonômicos \\
\hline Estufa & Acidentes, Físicos, Químicos \\
\hline Armário de Reagente & Químicos \\
\hline Geladeira & Físicos e Químicos \\
\hline Vidrarias & Acidentes \\
\hline
\end{tabular}

Tabela 01: Tipos de riscos por Local no Laboratório de Química de uma Escola Pública

A representação da Tabela 01 explica o mapa de risco do laboratório de química fazendo-se a leitura de todos os tipos de riscos ambientais. Os mais frequentes riscos encontrados foram: produtos químicos (Risco Químico), constância e repetitividade (Riscos Físico e Ergonômico) e choques elétricos (Risco de Acidente).

À postura inadequada é algo que atinge a maioria dos alunos no meio escolar, pois o aluno necessita de orientações sobre a forma correta de sentar e ter consciência de agir corretamente durante os experimentos. Um ponto que deveria ser precípuo em um laboratório é a presença do extintor, mas neste ambiente não tinha nenhum, cujo deveria estar, segundo a Norma Regulamentadora - NR 23 - Proteção Contra Incêndio, o extintor deve estar próximo à saída, para facilitar a aplicação do mesmo em prol da proteção coletiva.

O risco de acidente que também necessita de atenção é a probabilidade de incêndio ou explosão, pois o laboratório contém muitos reagentes e máquinas que utilizam a eletricidade para seu funcionamento, podendo causar algum dano ao ambiente e/ou ao profissional.

No risco de acidentes é ocasionado pela probabilidade de incêndio ou explosão. No armário contendo sais foi localizado em maior proporção o risco ergonômico, pois a necessidade de utilização deste é maior, ou seja, constância e repetitividade, além da imposição de ritmos excessivos. No caso do tipo químico dá-se por meio de substâncias compostas ou produtos químicos em geral. O armário de reagente é a que possui o maior grau no sentido de acidente e químico, pois nela é armazenado substâncias compostas e produtos químicos em geral de forma inadequada, além da probabilidade de incêndio ou explosão. Há ainda o risco ergonômico causado pela exigência de postura inadequada no armário onde se encontram vidrarias.

Portanto, é válido fomentar que o mapa de risco é essencial na prevenção de acidentes na esfera do laboratório de química, pois sua utilização torna-se necessária para ocasionar informações quanto aquela área, orientando os alunos e professores como se comportar.

\section{CONCLUSÕES}


Diante dos resultados obtidos foram detectados os riscos ambientais, apresentando com maior intensidade os riscos químicos, no processo de práticas de ensino. As identificações destes riscos são encontradas em estudos feitos por profissionais da área de segurança do trabalho, técnico em química e/ou agentes específicos, tanto na área profissional, tanto na área educativa, que cuja a função é orientar sobre os perigos, com simbologia, especificando por meio da norma de segurança, proporcionando o reconhecimento, a compreensão e conscientização dos alunos de que através da utilização de procedimentos de segurança no ensino se tenha a visão da abrangência da prevenção de acidentes, promoção da saúde e segurança.

Acredita-se que o meio escolar é o elo responsável em promover uma educação de qualidade através do desenvolvimento do espírito científico e do pensamento reflexivo, visando à formação técnica e humana dos alunos, para que ao se tornarem engenheiros, carreguem o compromisso de disseminarem o conhecimento adquirido, para melhoria da qualidade de vida da sociedade.

\section{REFERÊNCIAS}

BRASIL, Ministério da Saúde. Secretaria de Vigilância em Saúde. Vigilância ambiental em saúde: textos de epidemiologia. - Brasília: Ministério da Saúde, 2004.

DRUMMOND, C.; Mapa de riscos de acidentes do trabalho. Guia Prático. RMC,1994. 61 p.

LUCIANO, G.; Estruturação de um programa de gerenciamento de riscos na mineração de carvão. 2010. Monografia. Curso de Pós Graduação em Engenharia de Segurança o Trabalho, UNISUL, Tubarão.

NETO, N. C.; Mapeamento dos riscos. Segurança no trabalho em serviço e alimentação. Disponível em: <http: //www.td.utfpr.edu.br>. Acesso em: 09 Novembro 2014.

SANTOS, C. F. P.; Apostila Mapa De Risco, 1999.

SANTOS, M. S. T.; SENNE, S. H. L.; AGUIAR, S. R. L.; MARTINS, Y. A. Segurança e saúde no trabalho. ed. - São Paulo: IOB, 2010.

SIVIERI, L. H.; Saúde no Trabalho e Mapeamento dos Riscos, São Paulo, 1996

TEIXEIRA, P.; VALLE, S.; Biossegurança: uma abordagem multidisciplinar. Rio de Janeiro: Ed. Fio cruz, 1996.

VALlE, S.; BARREIRA, Y. (Orgs.). Biossegurança-Engenharia Genética: Legislação Brasileira. Rio de Janeiro: Publit, 2007. 